\title{
ARSENIC, NITRATE, AND CHLORIDE IN GROUNDWATER, OXFORD TOWNSHIP, OAKLAND COUNTY, MICHIGAN
}

\section{INTRODUCTION}

The U.S. Geological Survey (USGS) and the Center for Applied Environmental Research at the University of Michigan-Flint (CAER) mapped distributions of arsenic, nitrate, and chloride in the groundwater of Oakland County. Emphasis was placed on sites that exceeded Maximum Contaminant Levels (MCL) and Secondary Maximum Contaminant Levels (SMCL) set by the U.S. Environmental
Protection Agency. The maps were based on historical data from records compiled by the Michigan Department of Environmental Quality (MDEQ). The USGS collected and analyzed samples to test the water quality in a number of these wells to confirm the overall validity of the historical records. The maps showed that each of the chemical constituents is widely distributed. High concentrations of arsenic are most

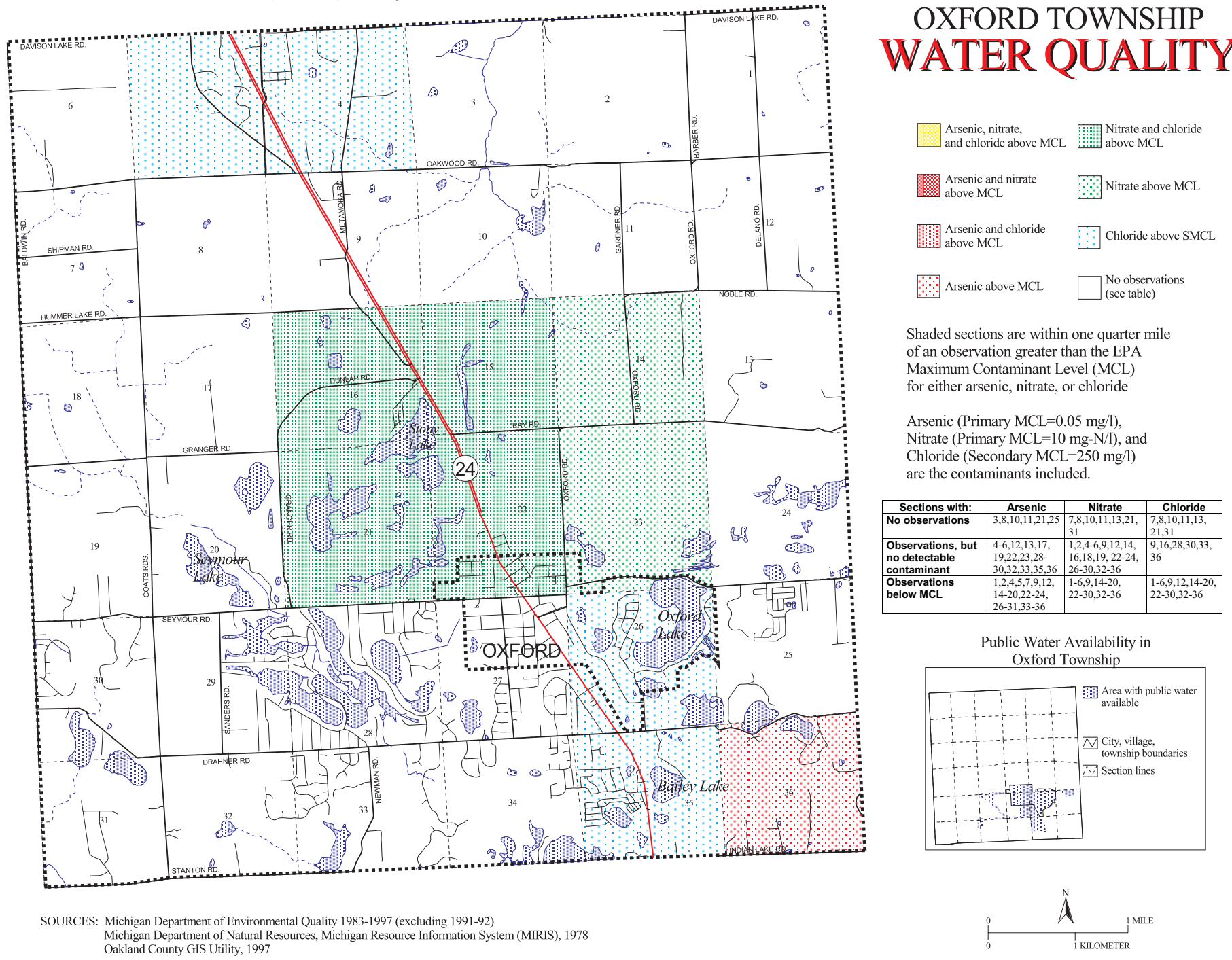

\section{HOW TO USE THE TOWNSHIP MAP}

Carefully review the map to find the approximate location of your home. If you find that your home is in one of the areas highlighted on the map, the Oakland County Health Division (OCHD) recommends that you obtain a water sample from your well to test for the contaminants indicated for that area. Contact the OCHD for information on obtaining sample bottles and procedures for collecting a sample. Homeowners with a well are, in effect, running their own small water utility. The best way to assure a safe drinking-water supply anywhere in Oakland County is to have water samples analyzed regularly by a certified public or private laboratory. Arsenic tests are conducted by the MDEQ. The OCHD can analyze samples for nitrate and chloride levels and also provide a list of certified private laboratories in the area who can test your water. 
common in the northern and northwestern parts of the county. Nitrate has been detected in groundwater in most townships but samples with concentrations above the MCL tend to cluster around high-density lakeshore communities. Chlorides are the most widely distributed and samples with concentrations above the SMCL also cluster in highdensity lakeshore communities.

To provide homeowners with more detailed information on the distribution of these water-quality indicators, a series of township maps have been prepared. These maps highlight square-mile sections that contain, or are close to, wells in which concentrations of arsenic, nitrate, or chloride greater than the (S)MCL have been detected.

\section{HOW WERE THE MAPS PREPARED?}

The MDEQ maintains a database of results from water-quality tests conducted for homeowners and businesses. In this study, maps were prepared from records of tests in Oakland County where arsenic, nitrate and chloride measurements were made. The data spanned the years from 1988 through 1997 (excluding 1991-92).

Addresses for each of the records were matched to an Oakland County road file through an address-matching procedure in a Geographic Information System. All sites with arsenic concentrations greater than the MCL were mapped. For nitrate and chloride, the success rates were 94 percent and 81 percent, respectively. Data coverage for all the chemical constituents was extensive, although the distribution of test results for arsenic was least concentrated in the southeastern part of the county, where public water supply is most available.
The township maps were prepared using the address-matched database and a detailed base map which included residential roads. Square mile sections were highlighted if they contained a well with a measurement higher than the (S)MCL for each constituent or were within a $1 / 4$-mile of one of these wells. These sections were shaded to indicate the multiple combinations of (S)MCL exceedances that were possible.

\section{HOW WERE THE SAMPLE DATA COLLECTED AND EVALUATED?}

The USGS collected water samples across Oakland County at selected sites with previous analyses for arsenic, nitrate or chloride. Each new sample was collected using clean sampling techniques to minimize the risk of contamination. Duplicate samples were sent to both the MDEQ laboratory and the USGS National Water Quality Laboratory (NWQL) in Denver, Colorado. Results from the USGS NWQL were compared against the results from MDEQ and against results from the previous samples. The results from the MDEQ laboratory agreed very closely with the results from the USGS NWQL. This sample testing confirmed the validity of using the MDEQ database in maps prepared for the study.

\section{by Steve Aichele (USGS), Richard Hill-Rowley (CAER), and Matt Malone (CAER)}

\section{WHAT CAN I DO IF I HAVE ARSENIC, NITRATE, OR CHLORIDE IN MY WATER?}

You may wish to have an additional sample collected to confirm the results of the first test. If your drinking water contains concentrations of arsenic or nitrate above the MCL, MDEQ and the OCHD recommend that you stop using the contaminated water for drinking and preparing food. Bottled water is a possible temporary solution. Neither arsenic nor nitrate pose a health risk through skin exposure, so the contaminated water can still be used for washing, laundry, and other household uses. Chloride is not generally considered to be a health concern.

Long-term solutions for high arsenic or nitrate concentrations include connecting to a public water supply, modifying the existing well or installing a new well, installing a treatment device such as a Reverse Osmosis (RO) filter, or using bottled water indefinitely. Chloride concentrations are a less serious concern than those associated with arsenic and nitrate and connecting to a public water supply or installing a treatment device such as a RO filter are the primary solutions.

Because treatment devices require regular maintenance to remain effective, MDEQ and Oakland County both recommend obtaining a new source of drinking water, either by connecting to a public water supply or, where high arsenic or nitrate concentrations are a concern, by drilling a new well.

The OCHD can provide additional information and advice on a solution to fit your needs.

\section{For more information, contact:}

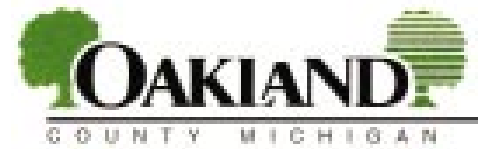

Oakland County Health Division

1200 N. Telegraph Road

Pontiac, MI 48341-0432

(248) 858-1312

http://www.co.oakland.mi.us

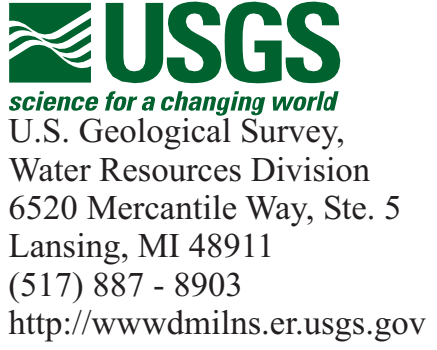

http://wwwdmilns.er.usgs.gov
University of Michigan-Flint

Center for Applied Environmental Research

University of Michigan - Flint

Room 529 Murchie Science Bldg.

Flint, MI 48502-2186

(810) 766-6608

http://www.umf-outreach.edu 